Review

\title{
VIDEO-ASSISTED THORACIC SURGERY (CONVENTIONAL AND SINGLE-PORT) - PLACE AND ROLE IN THE IMPROVED MANAGEMENT OF MALIGNANT PLEURAL EFFUSIONS: review article
}

\author{
D. Valchev ${ }^{1}$, E. Obretenov ${ }^{1}$, D. Petrov ${ }^{2}$ \\ ${ }^{1}$ Clinic of Thoracic Surgery, University Hospital Prof. Dr. St.Kirkovich, Medical Faculty of \\ Trakia University, Stara Zagora, Bulgaria \\ ${ }^{2}$ Clinic of Thoracic Surgery, University Hospital for Active Treatment of Pulmonary Diseases \\ "Sveta Sofia"EAD, Medical Faculty of Medical University, Sofia
}

\begin{abstract}
MPE management has been changing over the years as this is due both to the technological advancement of mini-invasive surgical methods and to the change in our knowledge about this manifestation of oncology disorder. Advanced cancer disease and poor general condition in most cases do not allow large-volume and duration of surgical procedures. VATS is becoming an increasingly large share of the operating methods of treatment of spontaneous pneumothorax, thoracic trauma, acute pleural empyema, pleural effusion, benign pleural and pulmonary lesions, secondary metastatic and primary malignant lesions - pleural, pulmonary, mediastinal and bilateral location. Diagnostic and therapeutic capabilities of VATS for simultaneous diagnosis and palliative surgical treatment make it the optimal procedure in MPE management. It should be noted that the preliminary assessment of the patient's condition and local status with an estimate of survival time often undergoes a radical change after the video-assisted surgical procedure. Improvement is reported with an increase of predetermined survival time and improved performance status, which supports the application of more minimally invasive, non-intubated, "awake" single-port VATS.
\end{abstract}

Key words and abbreviations: MPE-malignant pleural effusion, VATS-video-assisted thoracic surgery, pleurodesis.

\section{INTRODUCTION}

Malignant pleural effusions are an expression of an advanced oncological disease leading to a rapid deterioration in the overall condition of patients and a reduction in their physiological abilities. In Bulgaria, according to the National Cancer Registry, issue 2017, Volume $\mathrm{XXV}, 35265$ new cases of malignancies at a development rate of 1.50 were reported in 2015, while those who died from malignant diseases in 2015 were 17932, at a development rate of 1.15. Lung cancer is the most common malignancy in men $-18,5 \%$ of all new cases, while in women breast cancer is the most common $-26,8 \%$. These two cancer locations are the most frequent cause for death in men and women respectively: men - in 2015 26,1\%

\footnotetext{
*Correspondence to: Daniel Valchev, Clinic of Thoracic Surgery, University Hospital Prof. Dr. St.Kirkovich, Medical Faculty of Trakia University, Stara Zagora, Bulgaria; e-mail:

dg_valchev@abv.bg
}

of them died from lung and tracheal cancer; women - in $201517,4 \%$ died from breast cancer. Unfortunately, we do not have exact data on the average annual number of malignant pleural effusions in Bulgaria. The large number of patients with oncological diseases and the increased expectations of improving their quality of life, even after diagnosis of pleural effusion, require a change in the approach and management of MPE.

\section{PRESENTATION}

When considering the issue of MPE management, it should be noted that patients with advanced oncology disease are subject only to palliative surgical procedures aimed at improving performance status and quality of remaining life. At the same time, overall survival was unaffected or slightly affected and remains at medium range 6-12 months after the appearance of MPE. 
VALCHEV D., et al.

However, we should not forget that a considerable number of patients survive up to $3,4,5$, and sometimes more than 10 years, depending on a number of factors, such as: histological variant of primary neoplasm, adjuvant chemotherapy, target therapy, patient's comorbidity and various other predictors of survival. The treatment of MPE is palliative and aims at eliminating pleural effusion (not only passive evacuation, but also prevention of reappearance) with sufficient respiratory comfort and elimination of dyspnea symptoms. When examining the different surgical methods participating in MPE management, a number of questions need to be answered in depth, defining the indications for the use of any of them. These are: the requirement for minimal invasiveness, safety, high efficiency in diagnostic and therapeutic aspect, prospects for improvement of the methodology, possibility for quick dehospitalisation. According to many authors VATS method are in line with the answers of the above questions. Diagnosing the MPE is the most important task in patients with pleural effusion. Pleural effusion is diagnosed on the basis of medical history, objective examination findings and instrumental examinations - chest $\mathrm{X}$-ray and CT scan. Cytological (pleural fluid smears) and/or pathohistological (surgical biopsies) verifications are mandatory for MPE diagnosis. Not all proven malignant primary tumors are accompanied by a malignant pleural effusion. In some cases the so called paramalignant effusions are observed. They are not subject to specific therapy and the modality of management is different with them. However, it is mandatory to differentiate them from the MPE. The term "paramalignant effusion" refers tothose effusions thatoccur on the background of primary malignant disease but are not due to metastatic process on the pleura.The reasons may be different: pneumonia with parapneumonic effusion; thoracic duct obstruction with development of chylothorax due to radiation therapy; transudative effusions due to hypoalbuminemia with hypoproteinemia, congestive heart failure, reactiveeffusion due to inflammatory causes nearby and enudates from inflammatory processes in the pleural cavity. (1) The safest way to differentiate MPE from paramalignant pleural effusion in the absence of contraindications (Karnofsky index $<30$, or severe concomitant comorbidity) is to conduct any of the VATS procedures - conventional or single-port, non-intubation VATS under local potentiated anesthesia. VATS methods sensitivity to histological verification is also an important indicator for the assessment and importance of video-assisted surgery methods in MPE management. According to our data, both methods - single-port and conventional provide diagnostic yield, reaching almost $100 \%$, which makes video-assisted surgery a method of choice in MPE diagnosis. Compared to the sensitivity of cytological assessment of pleural fluid and the histological assessment of pleural biopsies taken by the Abrams method in thoracentesis, video-assisted surgery methods have one great advantage. According to Loddenkemper R. et al. and Antony V.B. et al. in a study of 208 patients with MPEthe diagnostic yield from cytology assessment of pleural fluid, obtained by pleural puncture, thoracentesis with a pleural catheter or any other method was $62 \%$. The yield from histological examination of closed pleural biopsy under Abrams method was 44\%, while histology results obtained through medical thoracoscopy amounted to $95 \%$. $(2,3)$ Other authors report that the diagnostic sensitivity of cytology, combined with closed needle pleural biopsies was $74 \%$, while the combined methods reached a diagnostic yield of $97 \%$ (4). Authors, comparing the diagnostic sensitivity of Abrams biopsy (blind percutaneous biopsy of the pleura) with Abrams CT-guided biopsy report the following data: $47 \%$ sensitivity, $100 \%$ specificity, for Abrams biopsy. The results obtained under CT-guided biopsy are as follows: $87 \%$ sensitivity, $100 \%$ specificity. The difference in sensitivity between Abrams biopsy and CT-guided biopsy amounts to $40 \%$ (5). In contrast, authors working with Videoassisted thoracic surgery report cytology diagnostic yield of $91-95 \%$. (1, 6).In our opinion VATS diagnostic sensitivity reaches up to $100 \%$, due to operators' experience in taking targeted biopsies from the right place and in the required depth, the mandatory waiting for express histological confirmation as well as adherence to the principle of an average number of 5-7 targeted biopsies. Video-assisted thoracic surgery appears to be the best method of diagnosis and palliative surgical treatment of malignant pleural effusions (4, 6-14). The visual assessment of changes in the pleural cavity as a visceral pleural and lung condition, an opportunity for reexpression assessment, the type and location of the lesions helps us to develop a behavioral algorithm in each case. $(2,10,14-20)$ The possibility of surgically influencing the changes observed, such as partial pleurectomy with debridement and liberalization of pulmonary parenchyma with improvement of pulmonary opposition and subsequent pleurodesis is essential for improving the MPE treatment outcomes $(1,6,8,21)$. According to 
VALCHEV D., et al.

Raza A. et al. the importance of VATS in the management of MPE with suspected diaphragmatic fenestration is irreplaceable. Diaphragmatic fenestration can be suspected when there is effusion at the same time in the pleural and peritoneal cavity. Verification for the presence of diaphragmatic fenestration is performed during the procedure VATS, since the existence of such leads to failure pleurodesis. (11) It is not by accident that most authors use the expression "gold standard" when writing about Video-assisted thoracic surgery for the treatment of malignant pleural effusions $(1,14,22)$. According to us and other authors, when after evacuation of the pleural fluid the sample for re expansion is negative and the lung remains trapped, pleurodesis should not be performed. Pleurodesis should not be performed if 24hour pleural fluid release through the pleural catheter exceeds 250-300ml. (2, 19) For patients without pleurodesis, patients with long-term secretion, trapped lung and those with failed pleurodesis and recurrence, most authors recommend intermittent pleural catheter placement by subcutaneous tunneling (IPC) or thoracostomy tube. The procedure is effective with relieving dyspnea and a low percentage of complications. $(12,22-28)$ The use of an IPC or permanent thoracostomy tube improves the quality of life by reducing dyspnea and increase their physiological capabilities even though they are at an endstage oncological disease. $(22,26,27)$ IPC application may lead to spontaneous pleurodesis in $46 \%-70 \%$ of the patients, showing complete lung reexpansion through local inflammatory changes, caused by the tumor, or the IPC. $(1,26) \mathrm{We}$, as well as other authors, share the opinion that in the cases where no pleurodesis is done due to pulmonary trap, and a permanent thoracostomy catheter is placed, approximately $30 \%$ of the patients achieve spontaneous reexpansion within 30 days. $(1,26)$ According to Ferreiro, L. et al. improper choice of healing strategy can lead to the progression of symptoms and shorten the life expectancy of MPE patients. (1) Some authors recommend that in the forthcoming VATS procedure pleurodesis for MPE the prognostic indicators of overall survival should be taken into account. Thus, the prognostic assessment aims at individualizing treatment strategies for MPE patients (29). According to Yoon D.W et al. preoperative chemotherapy, preoperative radiation therapy and Eastern Cooperative Oncology Group (ECOG) PS with performance assessment 3 or 4, are significant predictors of overall survival after VATS talc pleurodesis and are predictors of early death in patients who have undergone VATS talc pleurodesis. They should be considered when predicting life expectancy and determining the indications for VATS talc pleurodesis (30). Thus, the requirements to be met by candidates for video-assisted surgery are as follows: Karnofsky index $>30$, estimated survival time exceeding 3 months, no severe accompanying comorbidity/ congestive heart failure, IV class chronic heart failure, severe hypoproteinemia and hypoalbuminemia, liver cirrhosis, III stage kidney failure/. According to us and other authors in the cases of large pleural effusions, preliminary estimated of over $2000 \mathrm{ml}$. before the VATS procedure a pre-evacuation to 1300 $\mathrm{ml}$ of the whole quantity is advised. Evacuation is carried out from 24 to several hours before the procedure.This decreases significantly the possibility for intra- and postoperative complications such as: pulmonary edema, ARDS and heart and circulatory disorders, and leads to temporary improvement of ventilation, blood gas and performance status indicators $(12,31,32)$. This preliminary procedure also increases the percentage of eligible candidates for VATS, as well as the chances for intraoperative re-expansion of lung parenchyma. Some authors maintain the statement that the appearance of pleural effusion due to lymphomas is one of the factors that adversely affect overall survival in patients with lymphoma. The persistent pleural effusion, despite treatment, is associated with the failed outcome from the disease. Its appearance after chemotherapy and remission is a sign of relapse of the disease and leads to reduced survival. $(33,34)$ Another important criterion for treatment outcome is the lack of pleural effusion re-accumulation. In addition to the many factors influencing the efficiency of pleurodesis, it is of utmost importance to use the most efficient pleurodesis agents. Most authors worked on the topic described the talc as the most effective pleurodesant, with its two forms - talc poudrage and talc slurry, but their opinions on the efficacy of the two forms differ significantly. There are enough reliable studies confirming the fact that talc is considered to be the most efficient pleurodesis agent, while thoracoscopic talk pleurodesis is the most appropriate way for talc administration $(10,18$, $20,35,36)$. According to Shaw P. et al. proof of this is the aggregated data from 36 randomized controlled trials with 1499 patients, meeting the meta-analysis conditions (37). Two years after this study, Tan C. et al. unify the data from 46 randomized clinical trials covering a total of 2,053 patients with malignant pleural effusion. The authors confirm that talc is the most effective 
VALCHEV D., et al.

pleurodesant for pleurodesis in MPE. In the toracoscopic talc poudrage, less recurrence of effusion is reported than in talc slurry of pleurodesis. In contraindications to performing thoracoscopy, it is appropriate to perform a talc suspension pleurodesis. (38) The largest study is from 2016, where Clive A.O. et al. make network meta-analyzes of several randomized trials. Of the 1888 studies, 62 randomized trials were included, where a total of 3,428 patients who met the inclusion criteria. In conclusion, the authors state that, compared to other pleurodesants including doxacillin and bleomycin talc poudrage is the more effective method for pleurodesis in MPE. (29). Some of the authors argue that talc poudrage pleurodesis is not more efficient than talc slurry pleurodesis. In both cases, sustained pleurodesis is achieved, so they recommend pleurodesis with a talc suspension at the patient's bed via a pleural catheter. (39-41) Some authors examine not only the efficacy of talc as a pleurodesis agent, but its safe application as well. There are enough publications in scientific literature on the development of ARDS after thoracoscopic talk pleurodesis in MPE (42). Most authors, working on the safety of talc pleurodesis, claim that talc pleurodesis ( sterile, asbestos-free, calibrated talc with a particle size > 15 micrometers), applied as VATS talc poudrage of talc suspension with 2.5-10 g (4-6 g on average) talc is the most effective and safe method with a $93 \%$ success rate $(16,43,44)$. In cases of poor performance status and/or severely manifested comorbidities, the implementation of VATS talc pleurodesis is impossible. In cases where, after evacuation of the effusion there is pleural opposition and the estimated survival is more than 3 months, iodine-povidone pleurodesis can be performed through the pleural catheter. Thus, in the patients with MPE, who fall off as candidates for the procedure VATS, can be achieved effective control of pleural effusion through iodine-povidone pleurodesis. $(45,46)$ The size of the pleural catheters is important for the duration of the postoperative release of pleural fluid. Large pleural catheters with a caliber over 20 charriere are not preferable. First, because they trap the lung after surgery and do not allow it to deploy adequately, and secondly, their large contact surface with the pleural sheets causes irritation and prolonged secretion. Small pleural catheters with a caliber below 12 charriere are also ineffective because of frequent occlusion of protein conglomerates. Thus, after single-port VATS, one pleural catheter remains directed to the back sinus and is taken out through the operative port, with dimensions of 14-16 charrier. In conventional VATS procedure one or two pleural catheters with dimensions 18 charriere are used through the two lower ports. $(4,12,47)$ According to our experience, all drainages (pleural catheters) are put directly through the incision of the thoracic port, with no serious negatives reported and no need to use modified techniques of the thoracic port as proposed by Son B. S et al. (48). Described and introduced by many authors over the last few years methodology of non-intubation single-port and conventional VATS, performed under potentiated local anesthesia of breathing lung has increased the possibilities for these methods to be applied to patients with contraindications for general anesthesia with one lung ventilation $(6,8,13,17,49-58)$. All authors engaged with the topic claim, and we totally support them in our study, that there is no better way to deal with MPE than talc poudrage pleurodesis, performed together with a diagnostic assessment done by VATS methods $(1,2,4,6-11,16-20,29,32,37,38$, $43,47,50,56,59-62)$.

\section{CONCLUSION}

Advances in the development of mini-invasive thoracic surgery allowed the elaboration of new strategies to improve MPE management, includingmonitoring of pleural effusion, recurrent pleural evacuation,thoracostomy catheter orinternal pleural catheter, pleuroperitonealshunt (catheter) andVATS. These strategies must be consistent with the patient's overall well-being, expected survival, comorbidity, and patients take active role in the final decision. Thus VATS methods (conventional and single-port) take the lead among the methods for surgical palliative treatment in MPE management. With the inclusion of VATS- conventional and singleport in the management of MPE achieves maximum efficiency expressed in achieving lasting pleurodesis and control of pleural effusion with improving the quality of life and survival in this socially important group of patients.

\section{REFERENCES}

1. Ferreiro, L., Suárez-Antelo, J., Valdés, L., Pleural procedures in the management of malignant effusions. Ann Thorac Med, 12:3-10, 2017.

2. Loddenkemper, R., Mathur, P.N, Lee, P., Noppen, M., History and clinical use of thoracoscopy/pleuroscopy in respiratory medicine. ERS Breathe, 8: 144-155, 2011.

3. Antony, V.B., Loddenkemper, R., Astoul, P., Boutin, C., Goldstraw, P., Hott, J., Rodriguez Panadero, F., Sahn S.A., 
VALCHEV D., et al.

Management of malignant pleural effusions. European Respiratory Journal, 18: 402-419, 2001.

4. Nam, H.S., Malignant pleural effusion:medical approaches for diagnosis and management. Tuberc Respir Dis (Seoul), 76(5):211-217, 2014.

5. Maskell, N. A., Gleeson, F.V., Davies, R.J.,Standard pleural biopsy versus CTguided cutting-needle biopsy for diagnosis of malignant disease in pleural effusions: a randomised controlled trial. Lancet, 361(9366):1326-30, 2003.

6. Gradica, Fadil, Lisha, L., Gradica, Flora., Rexha, V., Argjiri, D., Bozaxhiu, D., Vata, Y., Bala, S., Kraja, P., Hafizi, H., Management of malignant pleural effusions. Journal of Thoracic Oncology, Volume 11, Issue 4, Supplement, Pages S138-S139, 2016.

7. Arapis, K., Caliandro, R., Stern, J.B., Girard, P., Debrosse, D., Gossot, D.,Thoracoscopic palliative treatment of malignant pleural effusions:results in 273 patients. Surg Endosc, 20 (6):919-23, 2006.

8. Muduly, D., Deo S., Subi, Ts., Kallianpur, A., Shukla, N.,An Update in the Management of Malignant Pleural Effusion. Indian J Palliat Care, 17(2): 98-103. 2011.

9. Musani A.I.,Treatment options for malignant pleural effusion. Curr Opin Pulm Med., 15(4):380-7, 2009.

10.Petrov, D., Kalaydzhiev, G.,Treatment of malignant pleural effusions. Surgery | MySurgery.bg, 17.03, 2014.

11.Raza, A., Amer, K.,Role of Vats in Management of Malignant Pleural Effusion with Suspected Diaphragmatic Fenestrations. Austin J Cancer Clin Res, 2(6): 1053, 2015.

12.Roberts, M.E, Neville, E., Berrisford, R.G., Antunes, G., Ali, N.J.,Management of a malignant pleural effusion:British Thoracic Society Pleural Disease Guideline 2010. Thorax, 65(Suppl 2):ii32-ii40, 2010.

13.Sayir, F., Cobanoglu, U., Mergan, D., Demir, H., Video-assisted thoracoscopic surgery for malignant pleural effusions. Asian Pac J Cancer Prev, 12(2):415-418, 2011.

14. Yankulov, A., Uchikov, A., Paskalev, G., Murdzhev, K., Prisadov, G., Hristov, Zh., Chapkanov, A., Uzunova, V., Dimitrov, I., Batashki, A., Uchikov, P., Role of videoassisted thoracic surgery for determining surgical behavior in patients with nonsmall cell lung cancer and pleural effusions. Magazine SURGERY, Volume LXV 2009 Issue 2-3, 2009.
15.Abumossalama, A.M., Abdelgawada, T.T., Sheblb, A.M., Malignant pleural effusion:Relationship between thoracoscopic findings and type of malignancy. Egyptian Journal of Chest Diseases and Tuberculosis, Volume 64, Issue 2, Pages 399-404, 2015.

16. American Thoracic Society, Management of malignant pleural effusions. Am J Respir Crit Care Med, vol 162:1987-2001, 2000.

17.Cox, S.E., Katlic, M.R.,Non-intubated video-assisted thoracic surgery as the modality of choice for treatment of recurrent pleural effusions. Ann Transl Med, 3(8):103, 2015.

18. Kalev, D., Bahavior in cases of malignant pleural effusions. Surgery | MySurgery.bg, 2011.

19.Loddenkemper, R., Lee, P., Noppen, M., Mathur, P.N., $\quad$ Medical thoracoscopy/pleuroscopy: step by step. ERS Breathe, 8: 156-167, 2011.

20.Stefani, A., Natali, P., Casali, C., et al.,Talc poudrage versus talc slurry in the treatment of malignant pleural effusion. A prospective comparative study. Eur $J$ Cardiothorac Surg, 30:827-32, 2006.

21.Rintoul, R.C., Ritchie, A.J., Edwards, J.G., et al., Efficacy and cost of video-assisted thoracoscopic partial pleurectomy versus talc pleurodesis in patients with malignant pleural mesothelioma (MesoVATS): an open-label, randomised, controlled trial. Lancet, 384:1118, 2014.

22.Bertolaccini, L., Viti, A., Terzi, A.,Management of malignant pleural effusions in patients with trapped lung with indwelling pleural catheter:how to do it. $J$ Vis Surg., 2: 44, 2016.

23.Freeman, R.K., Ascioti, A.J., Mahidhara, R.S.,A propensity-matched comparison of pleurodesis or tunneled pleural catheter in patients undergoing diagnostic thoracoscopy for malignancy. Ann Thorac Surg., 96(1):259-63, 2013.

24.Lombardi, G., Zustovich, F., Nicoletto, M.O., Donach, M., Artioli, G., Pastorelli, D. Diagnosis and treatment of malignant pleural effusion: a systematic literature review and new approaches. Am J Clin Oncol., 33(4):420-3, 2010.

25.Penz, E.D., Mishra, E.K., Davies, H.E., Manns, B.J., Miller, R.F., Rahman, N.M.,Comparing cost of indwelling pleural catheter vs talc pleurodesis for malignant pleural effusion. Chest, 146(4):991-1000, 2014.

26.Qureshi, R.A., Collinson, S.L., Powell, R.J., et al.,Management of malignant pleural effusion associated with trapped lung 
VALCHEV D., et al.

syndrome. Asian Cardiovasc Thorac Ann, 16:120-3. (2-), 2008.

27.Ried, M., Hofmann, H.S.,The treatment of pleural carcinosis with malignant pleural effusion. Dtsch Arztebl Int, 110(18):313-8, 2013.

28.Thomas, J.M., Musani, A.I., Malignant Pleural Effusions. Chest Medicine, 34, 459471, 2013.

29.Clive, A.O., Jones, H.E., Bhatnagar, R., Preston, N.J., Maskell, N.,Interventions for the management of malignant pleural effusions: a network meta-analysis. Cochrane Database Syst Rev, 8;( 5), 2016.

30.Yoon, D.W., Cho, J.H., Choi, Y.S., Kim, J., Kim, H.K., Zo, J.I., Shim, Y.M.,Predictors of survival in patients who underwent video-assisted thoracic surgery talc pleurodesis for malignant pleural effusion. Thorac Cancer, 7(4): 393-398, 2016.

31.Alar, T., Ozcelik, C., Single-incision thoracoscopic surgery of pleural effusions for diagnosis and treatment. Surg Endosc, 27(11):4333-6, 2013.

32.Raab, S., Siene,1 W., Beyer, M., Lampl, L., Treatment of malignant pleural effusion:consequent talc pleurodesis shows best results. Thorac cardiovasc Surg, 58V160, 2010.

33.Das, D.K.,Serous effusions in malignant lymphomas: a review. Diagn Cytopathol, 34(5):335-47, 2006.

34.Kostov, K., Ajderian, S.,Pleural effusions in haematologic malignancies. In Spiro Issue № 1 (25) Modern tendencies in lung diseases - 2013 Military medical academy, 2014.

35.Luh, S.P., Chen, C.Y., Tzao, C.Y.,Malignant pleural effusion treatment outcomes: pleurodesis via video-assisted thoracic surgery (VATS) versus tube thoracostomy. Thorac Cardiovasc Surg., 54(5):332-6, 2006.

36.Margaritora, S., Cesario, A., Vita, M.L., et al.,Single versus, multiple access videoassisted thoracic surgery in the treatment of malignant pleural effusion. Eur $J$ Cardiothorac Surg, 32:397, 2007.

37. Shaw, P., Agarwal, R.,Pleurodesis for malignant pleural effusions. Cochrane Database Syst Rev., (1):CD002916, 2004.

38.Tan, C., Sedrakyan, A., Browne, J., Swift, S., Treasure, T., The evidence on the effectiveness of management of malignant pleural effusion: a systematic review. Eur J Cardiothorac Surg, 29:829-38, 2006.

39.Debeljak, A., Kecelj, P., Triller, N., Letonj, S., Kern, I., Debevec, L., Rozman, A., Talc pleurodesis:comparison of talc slurry instillation with thoracoscopic talc insufflation for malignant pleural effusions. J BUON, 11 (4):463-7, 2006.

40.Dresler, C.M., Olak, J., Herndon, J.E., et al.,Phase III intergroup study of talc poudrage vs talc slurry sclerosis for malignant pleural effusion. Chest, 127 ( 3 ):909-915, 2005.

41.Yim, A.P., Cha, A.T., Lee, T.W., Wa, I.Y., Ho, J.K.,Thoracoscopic talc insufflation versus talc slurry for symptomatic malignant pleural effusion. Ann Thorac Surg, 62 (6):1655-1658, 1996.

42. Yankulov, A., Paskalev, G., Murdzhev, K., Uchikov, A., Chapkanov, A., Dimitrov, I., Bayashki, A.,Acute pneumonia in patients after talc pleurodesis for treatment of malignant pleural effusion (own study and literature survey). Surgery Magazine/SURGERYI, Volume LXIV Issue 4, 2008.

43.Janssen, J.P., Collier, G., Astoul, P., et al.,Safety of pleurodesis with talc poudrage in malignant pleural effusion:a prospective cohort study. Lancet, 369:1535-9, 2007.

44.Zarogoulidis, K., Zarogoulidis, P., Darwiche, K., et al.,Malignant pleural effusion and algorithm management. $J$ Thorac Dis., 5(suppl 4):S413-S419, 2013.

45.Mohsen, T.A., Zeid, A.A., Meshref, M., Tawfeek, N., Redmond, K., Ananiadou, O.G., et al.,Local iodine pleurodesis versus thoracoscopic talc insufflation in recurrent malignant pleural effusion:A prospective randomized control trial. Eur $J$ Cardiothorac Surg, 40:282-6, 2011.

46.Yankulov, A., Murdzheva, M., Paskalev, G., Murdzhev, K., Uchikov, A., Gradinarska,V., $\quad$ ChavdarovaG., Chapkanov,A., Pleural cytokines VEGF, IL-8, TGF- $\beta 1$, inducing pleural fibrosis after pleurodesis in patients with malignant pleural effusions. Thoracic Medicine, Volume IV, issue 3, 2012.

47.Rahman, N.M., Pepperell, J., Rehal, S., et al.,Effect of Opioids vs NSAIDs and Larger vs Smaller Chest Tube Size on Pain Control and Pleurodesis Efficacy Among Patients With Malignant Pleural Effusion: The TIME1 Randomized Clinical Trial. JAMA, 314:2641, 2015.

48.Son, B.S., Park, J.M., Seok, J.P., Kim, DH.,Modified incision and closure techniques for single-incision thoracoscopic lobectomy. Ann Thorac Surg, 99: 349-351, 2015.

49.Cajozzo, M., Lo Iacono, G., Raffaele, F., Anzalone, A.A., Fatica, F., Geraci, G., Dioguard, S.,Thoracoscopy in pleural effusion-two techniques: Awake singleaccess video-assisted thoracic surgery 
versus 2-ports video-assisted thoracic surgery under general anesthesia. Future Medicine Ltd. Future Oncol, n11(24s), 3941part, 2015.

50.Giudice, G., Lequaglie, C., Garramone, M., Marasco, D., QOL and efficacy of uniportal VATS for malignant pleural effusions. 18 Jahrestagung der Deutschen Gesellschaft für Thoraxchirurgie. Augsburg, Düsseldorf: German Medical Science GMS Publishing House, 2009.

51.Gonzalez-Rivas, D., Uniportal thoracoscopic surgery:from medical thoracoscopy to non-intubated uniportal video-assisted major pulmonary resections. Ann Cardiothorac Surg, 5(2):85-91, 2016.

52.Mineo, T.C., Sellitri, F., Tacconi, F., Ambrogi, V.,Quality of life and outcomes after nonintubated versus intubated videothoracoscopic pleurodesis for malignant pleural effusion: comparison by a casematched study. J Palliat Med, 17(7):761-8, 2014.

53.Mineo, T.C., Tamburrini, A., Perroni, G., Ambrogi, V.,1000 cases of tubeless videoassisted thoracic surgery at the Rome Tor Vergata University. Future Oncol, 12(23s):13-18, 2016.

54.Peters, M., Barnett, S., Gary Hammerschlag BSc., MBBS., FRACP.,Cancer Council Australia Lung Cancer Guidelines Working Party, What is the optimal management of malignant pleural effusions? Cancer Council Australia Lung Cancer Guidelines Working, 2016.

55.Salati, M., Brunelli, A.,Uniportal VATS for pneumothorax and interstitial lung disease. J Thorac Dis, 5(Suppl 3): S217-S220, 2013.
56.Simpson, G., Judge, D., Management of malignant pleural effusion. Respirology, 20, 169, 2015.

57.Tacconi, F., Pompeo, E., Non-intubated video-assisted thoracic surgery:where does evidence stand? J Thorac Dis, 8 (Suppl 4):S364-S375, 2016.

58. Yang, H.C., Moon, D.H., Jeon, J.H., Kim, M.S., and Lee J.M.,How to Minimize Wound Trauma in Single Incision Thoracoscopic Surgery.; SM J Pulm Med, 2(3): 1022, 2016.

59.Asghar, A., Rashid, M., Saeed, I., Bilal, U., Ali, M.Z., Khan, M.I., Subhani, S.,Comparison of Video Assisted Thoracoscopic Talc Pleurodesis to Pleurodesis through Chest Tube for Malignant Pleural Effusion. Pakistan Journal of Medical and Health Sciences, 5(2):297-302, 2011.

60.Barbetakis, N., Asteriou, C., Papadopoulou, F., Samanidis, G., Paliouras, D., Kleontas, A., Lyriti, K., Katsikas, I., Tsilikas, C.,Early and late morbidity and mortality and life expectancy following thoracoscopic talc insufflation for control of malignant pleural effusions:a review of 400 cases. J Cardiothorac Surg, 5:27, 2010.

61.Chen, J., Li, Z., Xu, N., Zhang, X., Wang, Y., and Lin, D.,Efficacy of medical thoracoscopic talc pleurodesis in malignant pleural effusion caused by different types of tumors and different pathological classifications of lung cancer. Int J Clin Exp Med, 8(10): 18945-18953, 2015.

62.Reddy, C., Ernst, A., Lamb, C., FellerKopman, D.,Rapid pleurodesis for malignant pleural effusions: a pilot study. Chest, 139:1419-1423, 2011. 